\title{
Comparison of dimensions of commercially available tractor drawn rigid cultivator tines
}

\section{Naveen Kumar and Ajay Kumar Sharma}

Received : 01.01.2020; Revised : 15.01.2020; Accepted : 01.02 .2020

See end of the Paper for authors' affiliation

Correspondence to :

C. Naveen Kumar Department of Farm Machinery and Power Engineering, College of Technology and Engineering, Maharana Pratap University of Agriculture and Technology, Udaipur (Rajasthan) India Email : naveenkumarc02@ gmail.com
ABSTRACT : Commercially available agricultural machines are not matching with standards which affect the performances. Many times, commercially available rigid cultivator tines used in tractor drawn cultivator do not match in dimensions as given in respective BIS code. A study conducted in Udaipur, Rajasthan revealed that out of four such tines only one tine $\mathrm{T}_{1}$ fulfilled the requirement of BIS code 7565:1975 whereas maximum deviation was observed for tine $\mathrm{T}_{2}$.

- KEY WORDS : Rigid cultivator, Tines, Hole diameter, Hole center to center distance

-HOW TO CITE THIS PAPER : Naveen Kumar, C. and Sharma, Ajay Kumar (2020). Comparison of dimensions of commercially available tractor drawn rigid cultivator tines. Internat. J. Agric. Engg., 13(1) : 1-4, DOI: 10.15740/HAS/IJAE/13.1/1-4. Copyright@ 2020: Hind Agri-Horticultural Society. 